\title{
Laboratory measurement of the functional and numerical responses of the predaceous mite, Typhlodromus (T.) setubali to Panonychus ulmi (Phytoseiidae: Tetranychidae)
}

Said OUASSAT ( $\nabla$ s.ouassat@edu.umi.ac.ma )

Universite Moulay Ismail https://orcid.org/0000-0003-3188-987X

Latifa Allam

Universite Moulay Ismail Faculte des Sciences

Research article

Keywords: Functional response; Attack rate; Handling time; Biological control; Typhlodromus (T.) setubali.

Posted Date: July 30th, 2020

DOI: https://doi.org/10.21203/rs.3.rs-37488/v1

License: (a) (1) This work is licensed under a Creative Commons Attribution 4.0 International License.

Read Full License 


\section{Abstract}

Background The functional response of a predator is one of the fundamental methods in ecological studies. Typhlodromus (T.) setubali (Dosse) is an indigenous predaceous mite recently re-described in Morocco. It was reported on various crops around the Mediterranean basin. This study aims to assess the functional response of $T$. (T.) setubali to the densities of $2,4,8,16,32,64$, and 128 immature stages of Panonychus ulmi under the controlled conditions of $26 \pm 1{ }^{\circ} \mathrm{C}, 65 \pm 5 \% \mathrm{RH}$ and $16: 8 \mathrm{~h} \mathrm{~L}$ : D photoperiod. The logistic regression was used to determine the functional response and the oviposition activity of predator females was followed to evaluate the numerical response. Thereafter, both parameters (the attack rate $(a)$ and handling time $\left.\left(T_{h}\right)\right)$ were estimated and the results were entirely discussed.

Results Logistic regression analysis revealed a Holling type II functional response, indicating that the number of $P$. ulmi killed by $T$. ( $T$.) setubali females increased as the prey density increased. The values of attack rate $(a)$ and handling time $\left(T_{h}\right)$ were 0.029 prey/ day and 0.573 prey, respectively. The oviposition of females increased above the prey density of $6.54 \mathrm{mites} / \mathrm{cm}^{2}$ and the highest value $(m)$ was 1.86 eggs/ day. Finally, the prey density needed to achieve half the maximum response $(n)$ was estimated to be 2.15 prey.

Conclusions The functional response analysis is one of the most rigorous methods for understanding the ecophysiology of a predator. The proportions of prey consumed by $T$. ( $T$.) setubali were higher at lower densities for $P$. ulmi immatures, implying that $T$. (T.) setubali should be more effective at suppressing the red spider mite populations at lower densities. Further laboratory-based studies are needed to draw biological conclusions.

\section{Background}

The functional response $[1,2]$ is one of the most commonly used mathematical models to describe the trophic interactions between a predator and its prey [3]. It is defined as the relationship between the prey density and the number of prey attacked by a single predator during a given time interval, for determining whether the functional response type of a predator is of type I, II, or type III. In biological control, the decision about which organism to use is strongly based on the results of such an analysis, which leads to drawing biological conclusions on a predator species [4], in combination with independent sources of information [5].

Several regression-based models describe the predation rate of a predator on various prey densities. Practically, the choice of one model to another constitutes a theoretical debate in terms of a complete analysis of a functional response data set [6]. Whenever possible, such investigation is one of the crucial methods to improve the biological control programs.

Holling (1959) [2] has defined three types of functional responses. In Type I, the number of consumed prey increases linearly to a maximum then remains constant as increasing prey density. In Type II, the number approaches the asymptote hyperbolically as prey densities increases. Whereas in Type III, the 
number of prey consumed approaches it as a sigmoid curve. Therefore, a clear distinction between type II and III based on predation is rather difficult [7]. Many published results reported that type II is the commonly frequent type among predators, especially, among predaceous mites belonging to the family Phytoseiidae [8-14].

The main objective of this study is to approach the functional response of the predaceous mite, $T .(T$. setubali Dosse (Acari: Phytoseiidae), to various densities of Panonychus ulmi (Koch) (Acari:

Tetranychidae), whether it is of type II or type III. Typhlodromus (T.) setubali is an indigenous phytoseiid adapted to the local climate in Morocco $[15,16]$, and lacking bibliographic information on its biology and predation rate is the first challenge of this study. Therefore, fitting functional and numerical responses data on $T$. (T.) setubalican help to improve its use as a biological control agent of pest mites and other crop insects in the agricultural Mediterranean areas, as long as it was reported in Tunisia, Israel, Greece, Jordan, Spain, Portugal, Slovakia and Germany [17].

\section{Results}

Functional Response of T. (T.) setubali

Estimates of the logistic regression coefficients are given in Table 1. The results indicate that $P_{0}, P_{1}, P_{2}$, and $P_{3}$ are significantly different from 0 . Further, as the linear coefficient, $P_{1}$ is negative $(P=0.007)$, the functional response type II model is the most appropriate for modelling the functional response of $T$. (T.) setubali females when fed on immature stages of $P$. ulmi at $26^{\circ} \mathrm{C}$.

Table 1

Estimates of the logistic regression model adjusted of $T$. (T.) setubali to P. ulmi prey densities.

\begin{tabular}{|c|c|c|c|c|}
\hline Coefficients & Estimate & SE & Error $z$ value & $P$ \\
\hline Intercept $\mathrm{P}_{0}$ & 4.98 & 0.78 & 5.96 & $<0.0001^{\star \star \star *}$ \\
\hline Linear $\mathrm{P}_{1}$ & -0.11 & 0.05 & -2.67 & $0.0075^{\star \star}$ \\
\hline Quadratic $\mathrm{P}_{2}$ & $1.9 .10^{-5}$ & $9.32 .10-6$ & 2.34 & $0.0161 *$ \\
\hline Cubic $\mathrm{P}_{3}$ & $-2.1 .10-7$ & 4.49.10-7 & -2.21 & $0.0271^{*}$ \\
\hline \multicolumn{5}{|c|}{ SE Standard Error } \\
\hline \multicolumn{5}{|c|}{ 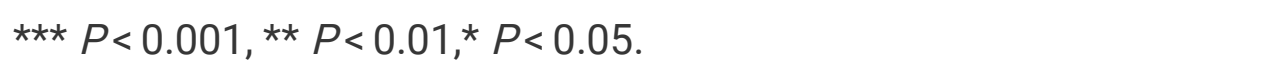 } \\
\hline
\end{tabular}

The logistic regression adjusting a polynomial equation of the proportion of prey attacked as function of prey density can be written as: 


$$
\frac{N_{e}}{N_{0}}=\frac{\exp \left(4.98-0.11+1.9 .10^{-5} N_{0}^{2}-2.1 .10^{-7} N_{0}^{3}\right)}{1+\exp \left(4.98-0.11+1.9 .10^{-5} N_{0}^{2}-2.1 .10^{-7} N_{0}^{3}\right)}
$$

The mean consumption rates of $T$. (T.) setubali females increased as prey density increased from 2 to 128 P. ulmi immatures, stabilizing at higher densities of 18 prey (Fig. 1a). At the low prey densities ranged from 2 to 16 , more than $90 \%$ of $P$. ulmi immatures were consumed. Although the prey density increased, the proportion of prey attacked decreased and the rate of consumption tended to stabilize beyond a prey density of 64 mites (Fig. 1b).

When Rogers's (1972) [21] model for a type II response (Eq. 2) was used to describe the functional response of $T$. (T.) setubali, both parameters, the attack rate $(a)$ and handling time $\left(T_{h}\right)$ were found to be significantly different from 0 and the model was capable of explaining $95 \%$ of the total variation in data (Table 2). The maximum predation rate is found as 34.48 prey/ day. Half of the maximum predation rate is attained at a density of $D=46.24$ prey corresponding to 6.54 prey $/ \mathrm{cm}^{2}$ (Fig. 1a).

Table 2

Estimate $( \pm$ SE) of the attack rate and handling time of $T$. (T.) setubali on immatures of Panonychus ulmi,

\begin{tabular}{|llllll|}
\hline Model & Parameters & Estimates & $\boldsymbol{P}$ & $95 \% \mathrm{Cl}$ & $\mathbf{R}^{2}$ \\
\hline Rogers (1972) & $a$ (prey/ day) & $0.573 \pm 0.022$ & $0.0037^{\star \star}$ & $0.438-0.674$ & 0.95 \\
\cline { 2 - 6 } & $T_{h}$ (day) & $0.029 \pm 0.051$ & $<0.0001^{\star \star \star}$ & $0.009-0.117$ & \\
\hline Hyperbolic & $m$ (eggs) & $1.862 \pm 0.611$ & $<0.0001^{\star \star \star}$ & $0.945-2.128$ & 0.89 \\
\cline { 2 - 6 } & $n$ (prey density) & $2.151 \pm 0.553$ & $0.0235^{\star}$ & & \\
\hline
\end{tabular}

\section{Numerical Response of T. (T.) setubali}

To assess the numerical response of $T$. (T.) setubali females, the hyperbolic model (Eq. 4) explained $89 \%$ of the total variation in daily oviposition rates (Table 2). The maximum daily oviposition $(m)$ of a $T$. (T.) setubali female was estimated to be 1.86 eggs/ day and the prey density needed to achieve half the maximum response $(n)$ was estimated to be 2.15 P. ulmi immatures (Fig. 2).

\section{Discussion}

Modeling a prey-predator system has progressed considerably to more mathematically fitted models, which correct errors related to certain classical aspects of calculation [24]. The logistic regression delivered a significantly negative linear coefficient $\left(P_{1}<0\right)$ and a positive quadratic coefficient $\left(P_{2}>0\right)$ for the seven classes of prey offered, suggesting that $T$. (T.) setubali performs a type II functional response to $P$. ulmi immatures (Table 1), which assumes that the predation rate increased according to the increase 
in prey density, levelling off to a maximum of 18 prey. The functional response curve (Fig. 1a) showed a high proportion of prey consumed at lower prey densities, The proportion of immature prey consumed by a predator $\left(N_{e} / N_{0}\right)$ declined with the increase of prey density (Fig. 1b). The estimated parameters were the attack rate $a=0.573$ prey $/$ day and handling time $T_{h}=0.029$ days per prey to Rogers's model (Table 2).

In this study, the handling time estimated for predator females of $T .(T$.$) setubali was relatively short,$ meaning that predators spend less time in capturing, killing, and digesting the prey. For example, the value estimated for $T$. (T.) setubali is similar to that obtained for Euseius concordis (Chant) adult females feeding on Oligonychus ilicis (McGregor) at $25^{\circ} \mathrm{C}$ (0.033 days) [13] and also to Neoseiulus cucumeris (Oudemans) on Thrips flavidulus (Bagnall), whereas it is significantly lower than those obtained for Neoseiulus barkeri (Hughes) and Euseius nicholsi (Ehara \& Lee) at $26^{\circ} \mathrm{C}$ in the same study $(0.042$ and 0.057 days, respectively), for which, the time taken during predation appears quite long [25].

The functional response alone cannot explain the success or failure of $T$. (T.) setubali as a biological control agent [26]. Several determining factors can affect its efficiency such as the intraguild predation [27], interactions with potential predators, properties of host plants [28], as well as abiotic factors such as temperature [29]. Although other experimental conditions of temperature and relative humidity, as well as the food diets, were not tested, $T$. (T.) setubali can capture and feed on prey without any initial delay in learning ways to circumvent difficulties.

Regardless of the host plants used in experiments, several authors have studied the functional responses of predatory mites on P. ulmi (Koch, 1836). For example, Euseius (Amblyseius) finlandicus (Oudemans) and Amblyseius andersoni (Chant) displayed a functional response of type II when exposed to increasing densities of larvae and adults of $P$. ulmi at $25^{\circ} \mathrm{C}$ [9]. Also, Typhlodromus (Typhlodromus) pyri (Scheuten), a generalist predator widely used in biological control, displays a functional response type II to $P$. ulmi at $25 \pm 1{ }^{\circ} \mathrm{C}, 75 \% \mathrm{RH}$, and a photoperiod of $16: 8$ (L: D)h [30]. The functional response of the phytoseiid predator Chileseius camposi (González y Schuster) on densities of $P$. ulmi under controlled temperature $20 \pm 2{ }^{\circ} \mathrm{C}$, relative humidity of $75 \pm 15 \%$ and photoperiod $16: 8 \mathrm{~h}$ (L:D) was found to be of type II [31]. The functional response of a predator can change from type II to III and vice versa in response to different factors described above.

\section{Conclusions}

Although this study was conducted on a predatory mite, the study of the functional response is an analytical model applicable to the whole scale of zoology in different types of Ecosystems. The present study demonstrated that the functional response of $T$. ( $T$.) setubali is of type II. The oviposition of the predator females increased curvilinearly with increasing prey density until reaching a plateau at densities from 32 to 128 P. ulmi immatures, with approximately 2.15 eggs/ female (Fig. 2), indicating that the relationship between prey density and oviposition increases with the predation rate. The female fecundity of phytoseiid mites depends strongly on the number of resources invested per egg [32]. Both functional 
and numerical responses of $T$. (T.) setubali females when fed on $P$. ulmi can be useful for determining the potentiality of this predatory mite and presents elementary information on this species. When more predators are candidates for use in biological control, the estimation of the functional response allows comparing the relative effectiveness of each one [33]. Therefore, our laboratory results may not exactly correspond to the situation in field, but this study will be helpful to further evaluate the feasibility of incorporating $T$. (T.) setubali in integrated pest management programs against $P$. ulmi on a wide variety of crops.

\section{Methods}

\section{Rearing mites}

Panonychus ulmi was collected from apple trees in Oulmes region, Morocco, and reared on green bean plants Phaseolus vulgaris L. (Leguminosae) for four generations before the beginning of the experiments. To obtain the seven densities that have been using in functional response experiments, the oviposition of Panonychus ulmi females was taken into account. Prey densities of 2, 4, 8, 16, 32, 64, and 128 immatures were obtained by transferring $1,3,5,10,16,34$, and 54 gravid females, respectively, onto the leaf discs. Females were allowed to lay eggs for 24 hours, then were removed. The eggs were followed daily once until to become immature forms, which will be used as food for predators.

The initial population of $T$. (T.) setubali was obtained from Riyad-Fruit orchard located at Tiddas, Morocco. The colony was kept in rearing unit and individuals were fed on immature stages of $P$. ulmi offered on been leaves. The rearing unit consists of black plastic tiles placed on a floating sponge into a plastic dish $(40 \times 27 \times 17 \mathrm{~cm})$ full of water. The bordering of the black plastic support was covered with a wet wide band of Kleenex to prevent mite escape. Been leaves infested by $P$. ulmi were added daily. Every week, bean leaves and water were exchanged with new ones. Rearing units were kept in growth chamber at $26 \pm 1{ }^{\circ} \mathrm{C}, 65 \pm 5 \% \mathrm{RH}$, and 16:8 $\mathrm{h}(\mathrm{L}: \mathrm{D})$ as photoperiod.

To obtain females of the same age, a total of fifty gravid females were transferred from the stock colony to a P. ulmi-infested been leaves placed in Petri dishes. The females were allowed to lay eggs for $12 \mathrm{~h}$ and then were removed. Newly emerged predators were of the same age.

\section{Functional and Numerical Response Experiments}

To assess the response of $T$. (T.) setubali to immatures of $P$. ulmi, $24 \mathrm{~h}$ starved predator females were assigned individually to one of seven prey densities $(2,4,8,16,32,64$ and 128 prey), corresponding to $0.28,0.56,1.13,2.26,4.52,9.05$ and 18.11 mites $/ \mathrm{cm}^{2}$, respectively. After $24 \mathrm{~h}$, the predator females were removed and the number of prey killed was counted. Collected data were fitted by using Logit-model.

The commonly used models do not detect the initial increase in attacks at the lower prey densities, because the predatory mites spend more time searching and handling prey even if confined into a smaller space such as a leaf disc [6]. For overcoming this problem, our experimental design involved ten 
replicates for mite densities of $0.28,0.56,1.13 \mathrm{mites} / \mathrm{cm}^{2}$, seven replicates for 2.26 , and $4.52 \mathrm{mites} / \mathrm{cm}^{2}$, and five for mite densities of 9.05 and $18.11 \mathrm{mites} / \mathrm{cm}^{2}$. All experiments were conducted at $26 \pm 1{ }^{\circ} \mathrm{C}, 65$ $\pm 5 \% \mathrm{RH}$, and 16:8 (L: D) h photoperiod.

To evaluate the numerical response of $T$. ( $T$.) setubali, the oviposition activity of females was followed for 4 consecutive days. The number of eggs deposited per female was recorded every $24 \mathrm{~h}$ in each replicate.

\section{Data analysis}

Functional response data set were analysed according to Juliano's procedure [18] using R Commander, a graphical user interface in conjunction with R program ver. 3.5.3. [19]. The logistic regression adjusting a polynomial equation (1) of the proportion of prey attacked $\left(N_{e}\right)$ as a function of the initial prey density $\left(N_{0}\right)$, was used to estimate the linear, quadratic and cubic coefficients and therefore, determined the shape of the functional response curve of $T$. (T.) setubali to immature stages of $P$. ulmi. The type of response was determined by the signs of the linear and quadratic coefficients $\left(P_{1}\right.$ and $\left.P_{2}\right)$. If the linear coefficient is negative $\left(P_{1}<0\right)$, it describes a type II functional response. If $P_{1}>0$ and $P_{2}<0$, it presents a type III functional response. Equation of the logit model includes an error $\varepsilon$, assuming to be distributed according to the binomial distribution [20]. (see Equation 1 in the Supplemental Files)

Where $N_{0}$ is the initial number of prey, $N_{e}$ is the number of prey eaten, $N_{e} / N_{0}$ is the probability of being attacked and $P_{0}, P_{1}, P_{2}$, and $P_{3}$ are the intercept, linear, quadratic, and cubic coefficients, respectively.

Regardless of the results obtained, the attack rate $(a)$ and handling time $(h)$ can be determined by using the Holing disc equation or Rogers's random predator equations of type II (2) and type III (3) [21], known as RRPE-II and RRPE-III. Rogers's random predator equations include an attack exponent $(q)$ to describe the per capita prey consumption in low prey densities and overcome the prey depletion at the end of experiments. Even if the number of attacked prey $\left(N_{e}\right)$ appears on both sides of equation (2), the fit of data is performed by using iterative Newton's method as an alternative to LambertW function one allows an explicit solution of the implicit RRPE-II [22]. For the functional response type III, a simplified version of the original model was presented by Hassell et al. (1977) [23] after a long series of research. The equations (2) and (3) makes it possible to predict how prey will be depleted over time during functional response experiments. (see Equations 2 and 3 in the Supplemental Files)

where $N_{e}$ is the number of prey consumed per predator during an exposure time $T(24 \mathrm{~h}), N_{0}$ is the initial number of prey, $a$ is the attack rate, $T_{h}$ is the handling time of prey by the predator and $P$ as the number of predators involving in experiments.

To describe the numerical response, the relationship between the fecundity of $T$. ( $T$.) setubali females and the prey density available was fitted by using a hyperbolic model (4), including the maximum daily 
oviposition $(m)$ and the density necessary for the predatory mite to oviposit half the maximum response $(n)$. (see Equation 4 in the Supplemental Files)

\section{Declarations}

\section{Acknowledgments}

We thank the managers of the Arbor and Riyad-fruits stations for providing the biological materials for this study.

\section{Authors' contributions}

AL performed the experimental design. SO analyzed and interpreted the results, and was a major contributor in writing the manuscript. All authors read and approved the final manuscript.

\section{Funding}

The Arbor Society provided funding for data analysis and writing up the project.

\section{Availability of data and materials}

The datasets used and analyzed during the current study are available from the corresponding author on reasonable request.

\section{Ethics approval and consent to participate}

This research was conducted in compliance with the regulations of the National Center for Scientific and Technical Research and the Moroccan Institute of Scientific and Technical Information.

\section{Consent for publication}

Not applicable.

\section{Competing interests}

The authors declare that they have no competing interests.

\section{References}

1. Solomon ME. The Natural Control of Animal Populations. Journal of Animal Ecology. 1949;18:1-35.

2. Holling CS. The Components of Predation as Revealed by a Study of Small-Mammal Predation of the European Pine Sawfly1. The Canadian Entomologist. 1959;91:293-320. 
3. Jeschke JM, Kopp M, Tollrian R. Predator Functional Responses: Discriminating Between Handling and Digesting Prey. Ecological Monographs. 2002;72:95-112.

4. Carroll RJ, Ruppert D. Transformation and Weighting in Regression. CRC Press; 1988.

5. Casas J, Hulliger B. Statistical analysis of functional response experiments. Biocontrol Science and Technology. 1994;4:133-45.

6. Okuyama T. On selection of functional response models: Holling's models and more. BioControl. 2013;58:293-8.

7. Rosenbaum B, Rall BC. Fitting functional responses: Direct parameter estimation by simulating differential equations. Methods in Ecology and Evolution. 2018;9:2076-90.

8. Badii MH, McMurtry JA. Effect of prey density on functional and reproductive responses of the predatory mite Phytoseiulus longipes (Acari: Phytoseiidae). International Journal of Acarology. 1988;14:61-9.

9. Koveos DS, Broufas GD. Functional response of Euseius finlandicus and Amblyseius andersoni to Panonychus ulmi on apple and peach leaves in the laboratory. Exp Appl Acarol. 2000;24:247-56.

10. Kasap I, Atlihan R. Consumption rate and functional response of the predaceous mite Kampimodromus aberrans to two-spotted spider mite Tetranychus urticae in the laboratory. Exp Appl Acarol. 2011;53:253-61.

11. Farazmand A, Fathipour Y, Kamali K. Functional response and mutual interference of Neoseiulus californicus and Typhlodromus bagdasarjani (Acari: Phytoseiidae) on Tetranychus urticae (Acari: Tetranychidae). International Journal of Acarology. 2012;38:369-76.

12. Fathipour Y, Karimi M, Farazmand A, Talebi Ali A. Age-specific functional response and predation capacity of Phytoseiulus persimilis (Phytoseiidae) on the two-spotted spider mite. Acarologia. 2017;58:31-40.

13. da Silveira EC, Reis PR, Siqueira MF, Toledo MA, Liska GR, Cirillo MÂ. Functional response of Euseius concordis feeding on Oligonychus ilicis (Acari: Phytoseiidae, Tetranychidae). Exp Appl Acarol. 2020;14:371-382.

14. Bazgir F, Shakarami J, Jafari S. Functional response of the predatory mite Amblyseius swirskii (Acari: Phytoseiidae) to Eotetranychus frosti (Tetranychidae) and Cenopalpus irani (Tenuipalpidae). Acarologia. 2020;60:30-9.

15. McMurtry JA, Bounfour M. Phytoseiid mites of Morocco, with descriptions of two new species and notes on the genera Kuzinellus, Typhloctonus, and Typhlodromus (Acari, Phytoseiidae). Acarologia. 1989;30:13-24.

16. Tixier M-S, Kreiter S, Allam L, Ouahbi A, Hmimina M. Phytoseiid, and tetranychid mites (Acari: Mesostigmata, Prostigmata) of some Moroccan crops. Acarologia. 2003;43:87-97.

17. Tixier M-S, Allam L, Douin M, Kreiter S. Phytoseiidae (Acari: Mesostigmata) of Morocco: new records, descriptions of five new species, re-descriptions of two species, and key for identification. Zootaxa. 2016;4067:501-51. 
18. Juliano SA. Nonlinear curve fitting: predation and functional response curves. In: Scheiner, S.M. and J. Gurevitch (eds.)-Design and Analysis of Ecological Experiments. New York: Oxford University Press; 2001. p. 178-96.

19. R Core Team. A language and environment for statistical computing. Vienna, Austria: R Foundation for Statistical Computing; 2019.

20. Rutherford A. Introducing Anova and Ancova: A GLM Approach. SAGE; 2001.

21. Rogers D. Random Search and Insect Population Models. Journal of Animal Ecology. 1972;41:36983.

22. Pritchard D. frair: Tools for Functional Response Analysis. 2017. https://github.com/dpritchard/frair.

23. Hassell MP, Lawton JH, Beddington JR. Sigmoid Functional Responses by Invertebrate Predators and Parasitoids. Journal of Animal Ecology. 1977;46:249-62.

24. Zhang JF, Papanikolaou NE, Kypraios T, Drovandi CC. Optimal experimental design for predator-prey functional response experiments. Journal of The Royal Society Interface. 2018;15:20180186.

25. Yao H, Zheng W, Tariq K, Zhang H. Functional and Numerical Responses of Three Species of Predatory Phytoseiid Mites (Acari: Phytoseiidae) to Thrips flavidulus (Thysanoptera: Thripidae). Neotrop Entomol. 2014;43:437-45.

26. Gangisaffat F, Perring TM. Prey stage preference and functional response of the predatory mite Galendromus flumenis to Oligonychus pratensis. Biological Control. 2015;82:40-5.

27. Sentis A, Hemptinne JL, Brodeur J. How functional response and productivity modulate intraguild predation. Ecosphere. 2013;4:art46.

28. Barbosa M FC, Poletti M, Poletti E C. Functional response of Amblyseius tamatavensis Blommers (Mesostigmata: Phytoseiidae) to eggs of Bemisia tabaci (Gennadius) (Hemiptera: Aleyrodidae) on five host plants. Biological Control. 2019;138. DOl:10.1016/j.biocontrol.2019.104030.

29. Jalali MA, Tirry L, De Clercq P. Effect of temperature on the functional response of Adalia bipunctata to Myzus persicae. BioControl. 2010;55:261-9.

30. Wei Q, Walde SJ. The functional response of Typhlodromus pyri to its prey, Panonychus ulmi: the effect of pollen. Exp Appl Acarol. 1997;21:677-84.

31. Sepúlveda F, Carrillo R. Functional response of the predatory mite Chileseius camposi (Acarina: Phytoseiidae) on densities of it prey, Panonychus ulmi (Acarina: Tetranychidae). Revista de Biología Tropical. 2008;56:1255-60.

32. de Moraes GJ, McMurtry JA. Comparison of Tetranychus evansi and T. urticae [Acari: Tetranychidae] as prey for eight species of phytoseiid mites. Entomophaga. 1985;30:393-7.

33. Rodríguez Morell H, Miranda I, Ramos M, Badii M h. Functional and numerical responses of Amblyseius largoensis (Muma) (Acari: Phytoseiidae) on Polyphagotarsonemus latus (Banks) (Acari: Tarsonemidae) in Cuba. International Journal of Acarology. 2010;36:371-6.

\section{Figures}



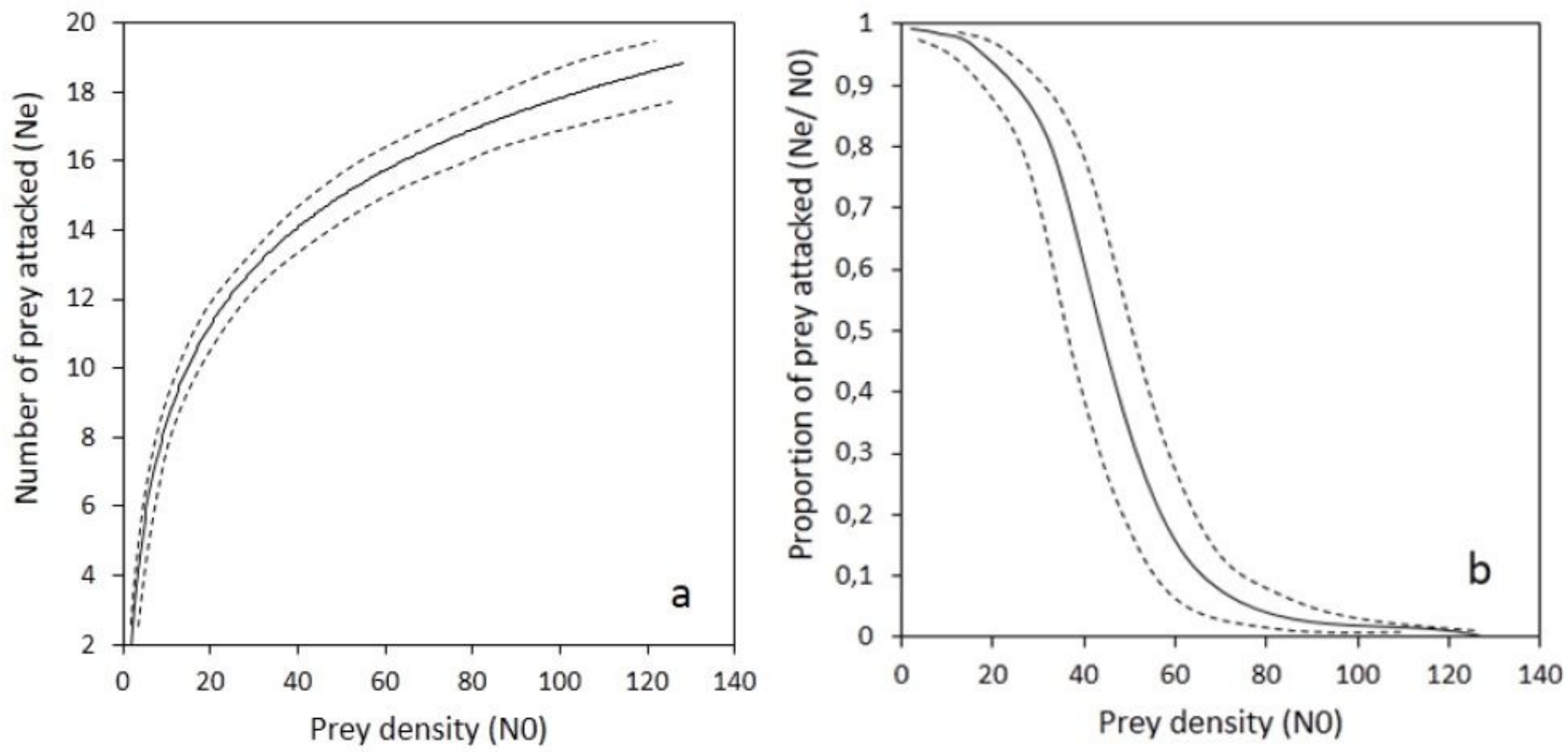

\section{Figure 1}

a: Mean number of Panonychus ulmi immatures killed per day by a female Typhlodromus (T.) setubali $(\mathrm{Ne})$, based on Rogers's random disc equation. b: Mean proportion of Panonychus ulmi attacked by a Typhlodromus ( $\mathrm{T}$.) setubali female (Ne/N0) at increasing densities of Panonychus ulmi immatures. In both illustrations, the dashed lines are the $95 \%$ confidence limits. 


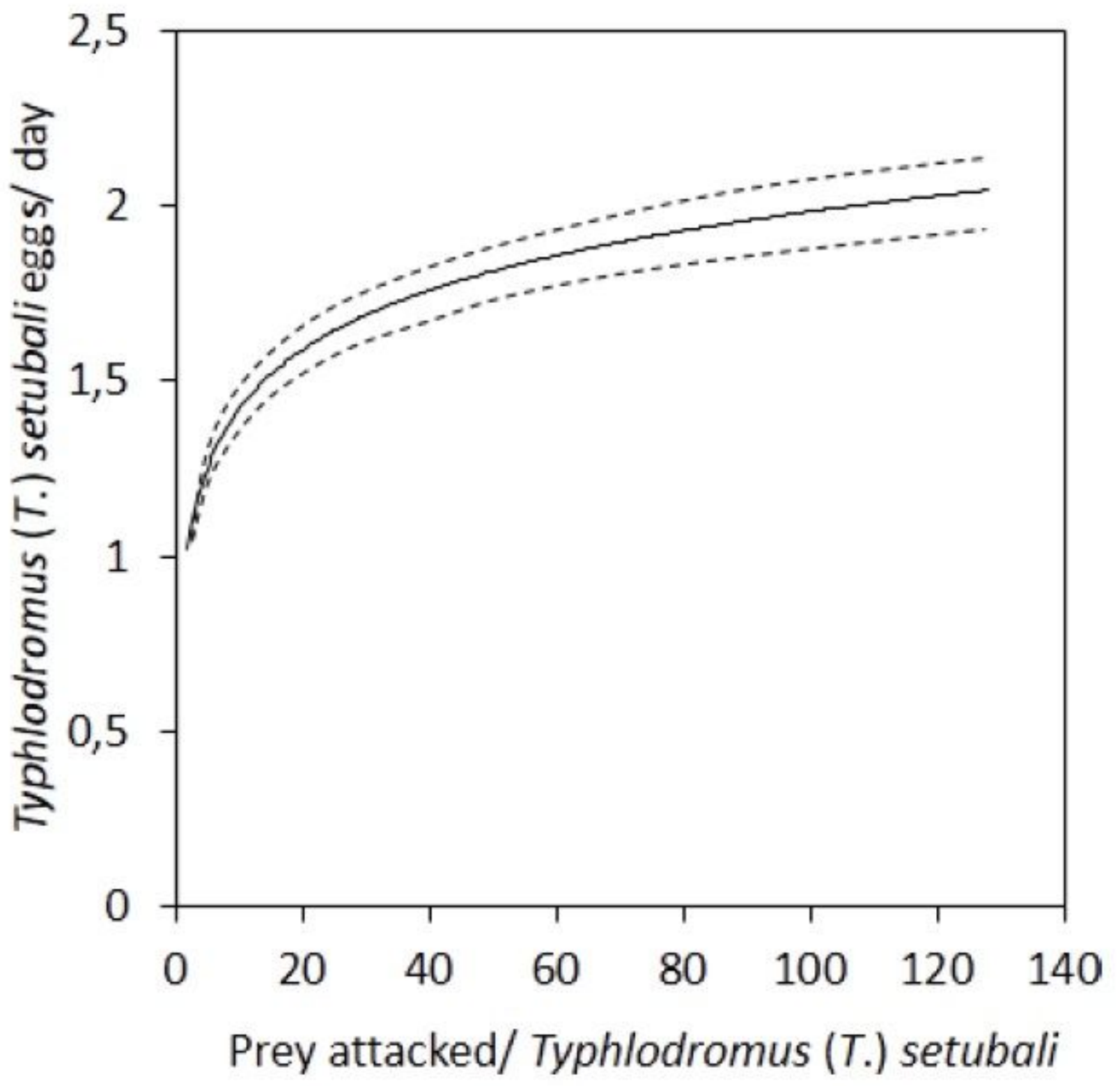

Figure 2

Mean ( \pm SE) number of eggs produced per day by a Typhlodromus (T.) setubali female when exposed to increasing densities of Panonychus ulmi immatures. The line shows the predicted relationship based on a hyperbolic model (equation 3 ) with $95 \%$ confidence intervals as dashed lines.

\section{Supplementary Files}

This is a list of supplementary files associated with this preprint. Click to download.

- Equations.pdf 